\title{
Two-stage agglomeration of fine-grained herbal nettle waste**
}

\author{
Stawomir Obidziński*, Magdalena Joka, and Olga Fijot \\ Department of Agricultural, Food and Forestry Engineering, Faculty of Civil and Environmental Engineering, \\ Białystok University of Technology, Wiejska 45E, 15-351 Białystok, Poland
}

Received July 13, 2016; accepted July 3, 2017

\begin{abstract}
This paper compares the densification work necessary for the pressure agglomeration of fine-grained dusty nettle waste, with the densification work involved in two-stage agglomeration of the same material. In the first stage, the material was pre-densified through coating with a binder material in the form of a $5 \%$ potato starch solution, and then subjected to pressure agglomeration. A number of tests were conducted to determine the effect of the moisture content in the nettle waste $(15,18$ and $21 \%$ ), as well as the process temperature $\left(50,70,90^{\circ} \mathrm{C}\right)$ on the values of densification work and the density of the obtained pellets. For pre-densified pellets from a mixture of nettle waste and a starch solution, the conducted tests determined the effect of pellet particle size $(1,2$, and $3 \mathrm{~mm})$ and the process temperature $(50$, $70,90^{\circ} \mathrm{C}$ ) on the same values. On the basis of the tests, we concluded that the introduction of a binder material and the use of two-stage agglomeration in nettle waste densification resulted in increased densification work (as compared to the densification of nettle waste alone) and increased pellet density.

Keywords: agglomeration, nettle waste, binder, starch
\end{abstract}

\section{INTRODUCTION}

One of the types of post-production waste produced in herbal companies is the nettle waste obtained during herb processing. The amount of waste left over from the process of herbal production is relatively large, with its utilisation being problematic due to the very small particle sizes of waste fractions.

In the case of Herbapol Białystok S.A., the annual production of herbal (usually nettle) waste, amounting to approx. $30 \mathrm{t}$, is usually sold cheaply or given away for a refund of the transport price.

*Corresponding author e-mail: s.obidzinski@pb.edu.pl

**This research was financed from funds assigned for statutory activity S/WBIŚ/2/2015 performed in Department of Agricultural, Food and Forestry Engineering on the Faculty of Civil and Environmental Engineering of Białystok University of Technology (2015 -2017).
The most common method of herbal waste management is using herbal waste as a fodder additive. Depending on the species of the plant used, herbs exhibit bactericidal (e.g. sage), immunostimulating (Echinacea), antioxidant (e.g. rosemary), sedative, and soporific (e.g. melissa) properties. They can also lower cholesterol levels in the body. In addition, some of these improve the aroma and flavour of fodder. In order to take advantage of this range of properties, mixtures of different plants are often used (Hanczakowska, 2007). The effect of herbal additives in pig fodder on nutritional results is presented in a paper by Paschma (2004), among other studies.

One of the methods of plant biomass waste management, including fine-grained herbal waste, is its pelleting or briquetting into a solid fuel (pellets, briquettes), and then using the resulting product as fodder or fuel (subjecting it to combustion). Various kinds of post-production plant waste have been densified into the form of pellets or briquettes: olive tree pruning residues (Carone, 2010), cork powder waste (Montero et al., 2014), blends of poplar and pine sawdust (Monedero et al., 2015), corn stover and switchgrass (Mani et al. 2006a, 2006b), rice straw and rice bran (Chou et al., 2009), herbaceous crops (Gilbert et al., 2009), mixtures of fine-grained tobacco and lemonbalm waste (Obidziński, 2012a), mixtures of potato pulp and buckwheat hulls (Obidziński, 2014a; Obidziński et al., 2016), mixtures of potato pulp and oat bran (Obidziński, 2014b), different mixtures of vine shoots and cork (Mediavilla et al., 2009), spent mushroom compost-coal (Ryu et al., 2008), and other plant mixes (Niedziółka et al., 2008).

(C) 2017 Institute of Agrophysics, Polish Academy of Sciences 
The main issue with the utilisation of fine-grained herbal waste is its low bulk density $\left(<300 \mathrm{~kg} \mathrm{~m}^{-3}\right)$ and the extremely small particle sizes. This is hugely problematic as far as its use as a material for pressure agglomeration is concerned, due to the significant effect of densification work on the process, as compared to the densification work for larger particles of the same material. It is as well problematic because of the issues caused by the dusty fraction's coating (gluing) of the elements of the working system (densification rolls, matrix, piston) during densification. The effect of these issues is that such materials are usually subjected to non-pressure agglomeration.

According to Sobczak (2004), non-pressure agglomeration makes it possible to produce dusty particles in small volumes, which, as noted by Obraniak and Gluba (2011), is a cost-effective solution due to the relatively small investment expenditures and operational costs it involves, provided that a suitable binding liquid is selected and appropriate process parameters are set.

Gluba (2003) argues that the course of non-pressure agglomeration, and, in consequence, the properties of the obtained product, depend on the properties of both media involved in the process, in addition to the design parameters of the device and the processing conditions. This is corroborated by Wildeboer et al. (2005).

According to Gluba and Obraniak (2009), the commonly used pelleting methods provide ready-made products with the desired quality parameters. However, if the range of parameters is narrowed down, the means and methods for refining the existing pelleting processes need to be identified, in addition to designing new, more effective means and methods intended for a specific product.

Moreover, it is advisable to seek new methods of dustymaterial pelleting, since non-pressure agglomeration fails to deliver products with adequate durability properties, and which are resistant to storage and transport conditions and hold sufficiently long life (in the case of fodder material).

Therefore, a method needs to be designed that would help to obtain a product with adequate durability properties, and, at the same time, alleviate the problems with the elements of the working system being coated (glued) during the densification process. These problems result in such materials being typically subjected to non-pressure agglomeration. The solution in this case is to use a specific type of two-stage agglomeration, i.e. non-pressure agglomeration, followed by pressure agglomeration.

A similar approach is presented in the literature dealing with the agglomeration of plant materials. Shipe et al. (2012) claim that one way to improve pellet quality is simply to supply more mechanical energy, either by using a thicker matrix, an expander, or double pelleting. All of these techniques increase the amount of electrical energy needed to produce a ton of pellets. According to Payne et al. (2001), double pelleting is a process whereby a conditioned feed enters the top press, where it is pre-densified through a 'thin' matrix. The pre-formed pellets then pass to the bottom press fitted with a matrix whose specification is determined by the requirements of the finished product. However, some feeds do not require double pelleting and therefore pass only through the bottom press. Payne et al. (2001) claim that if an excessive amount of short ends is found in the finished pelleted product when double pelleting, then it is possible that the specification for the matrix of the top press is too strict. Payne et al. (2001) state that it is important to use optimum matrix specifications for efficient production when double pelleting.

Robohm and Apelt (1989) hold that double pelleting improves the hardness and durability of feed pellets with a high fibre content, as well as those with high fat levels. Robohm and Apelt (1989) explain that a typical double pelleting system consists of two presses connected to each other in series. The first press, equipped with a conventional barrel-type conditioner and a relatively thin matrix (e.g. $5.0 \mathrm{~mm}$ in diameter and $25.0 \mathrm{~mm}$ in length) is used to pre-densify the feed. The second press is equipped with a thicker matrix (e.g. $5.0 \mathrm{~mm}$ in diameter and $40.0 \mathrm{~mm}$ in length). Robohm and Apelt (1989) claim that the drawback of a double pelleting system is that it requires more specific amounts of energy for pelleting.

According to Hryniewicz et al. (2008) and other researchers (Flore et al., 2009; Herting and Kleinebudde, 2007), two-stage pelleting is a novel process whereby a fine-grained material is consolidated, usually in roll presses, and then crushed and divided into grain classes. The half-product thus obtained has a larger bulk density and a lower required degree of density. As two-stage pelleting is used in the pharmaceutical industry, it is being continuously improved. Also, it is increasingly used to manufacture final products, e.g. certain fertilisers.

The aim of this paper is to compare the densification work during the process of pressure agglomeration of finegrained dusty nettle waste and the properties of pellets obtained under various conditions, with the densification work and the properties of pellets obtained during a twostage pressure agglomeration of the same material, i.e. material pre-densified in the process of non-pressure agglomeration with a binder addition and then subjected to pressure agglomeration.

\section{MATERIALS AND METHODS}

Post-production nettle waste (from Herbapol Lublin S.A., Branch Office in Białystok; a by-product of the manufacturing of herbal additives to medicines) was used as the test material subjected to pressure agglomeration (pelleting).

Bulk density tests showed that the tested nettle waste is characterised by a low bulk density of approximately $234 \mathrm{~kg} \mathrm{~m}^{-3}$. This is of significance as far as long-haul 
transport of waste is concerned, as such a low density makes transport difficult. By extension, it is advisable to aim at reducing the volume of the transported raw material.

The average moisture content in nettle waste obtained from the manufacturer (Herbapol Lublin S.A. Branch Office in Białystok) was $8.6 \%$, a value too low for the densification process to take place. Therefore, the material was moistened to assume the desired moisture content of 15,18 , and $21 \%$. This was done by adding a specific (pre-calculated) amount of water to a known mass of nettle waste (initial moisture content: $8.6 \%$ ). This involved spraying the nettle waste with a (pre-calculated) amount of water and then enclosing it in sealed plastic packages and putting it aside for $24 \mathrm{~h}$ to equilibrate the moisture throughout the volume.

The two-stage agglomeration of nettle waste consisted of preliminary densification (non-pressure pelleting) and secondary densification (pressure pelleting). During preliminary densification, in the process of coating, a binder in the form of a $5 \%$ potato starch solution was added. The starch used in the tests was obtained from the Peepes S.A. plant in Łomża.

The preliminary densification of nettle waste with binder content was done using non-pressure pelleting through coating; for non-pressure pelleting, a test stand was used. The design and operation of the stand is explained in a paper by Hejft and Leszczuk (2011).

In the process of non-pressure pelleting, nettle waste was fed to the charging hopper above the feeder to direct the stream of shredded ingredients to the appropriate spots on the pelleting plate. The pelleting liquid (a 5\% starch solution) was fed over the pelleting plate (at two points) from a pressure tank through a set of nozzles. The stream of raw material dosed from the feeder and the stream of sprayed pelleting liquid met on the rotating plate of the pellet mill. The rotational speed of the plate was controlled by means of a single-phase motor with a converter. The contact between the shredded raw material and the pelleting liquid, coupled with the pouring motion of the material, produced pellets with a distinct round shape.

The non-pressure pelleting of nettle waste with binder content was done with the technological parameters set as follows: the inclination angle of the pelleting plate at $50^{\circ}$; the angle of the blade set in the pelleting plate at $90^{\circ}$; the rotational speed of the plate at 48 r.p.m.; the mass of nettle waste on the plate $-500 \mathrm{~g}$; binder mass $-150 \mathrm{~g}$; pelleting time $-16 \mathrm{~min}$; the flow rate of the pelleting liquid $-0.0251 \mathrm{~min}^{-1}$.

Pressure agglomeration (pelleting) tests of nettle waste and mixtures of nettle waste and a binder pre-densified in the process of coating were performed on an SS-3 stand (with the 'open densification chamber - densification piston' working system), as presented in Obidziński (2012a, 2012b)
The stand consists of a hand press mounted on the base of an open densification chamber with a $9 \mathrm{~mm}$ opening. The densification chamber is heated (by a heating band placed from the top down a special heat exchanger), allowing control over the process temperature. The preset temperature is reached by means of a temperature controller coupled with the heating band. The material is then densified by means of a densification piston with a strain gauge. This set-up allows the recording of the forces on the piston. Signals from the strain gauge system attached to the densification piston and the side pistons, as well as signals from the displacement sensor, are transmitted by a Spider 8-type multichannel recorder coupled with a computer, where they are recorded in the form of binary files, and then processed further.

The pressure agglomeration tests consisted of the following stages:

- preparation (moistening) of nettle waste to achieve the desired moisture content levels;

- preliminary densification of nettle waste through nonpressure agglomeration in a flat-plate pellet mill, with binder content in the form of a $5 \%$ starch solution;

- pressure agglomeration (pelleting) of nettle waste and pre-densified pellets (after $24 \mathrm{~h}$ ) on an SS-3 test stand;

- determination of the density of the pellets obtained through pressure agglomeration ( $24 \mathrm{~h}$ after leaving the working system).

Once these stages had been completed, we determined the moisture contents of the nettle waste, the pellets obtained through non-pressure agglomeration, and the pellets obtained through pressure agglomeration.

The moisture content in the tested material (nettle waste and a mixture of nettle waste and a 5\% potato starch solution) was assessed in line with PN-EN 14774-1:2010, by means of a WPE $300 \mathrm{~S}$ scale-dryer with an accuracy of $0.01 \%$. Each time, we determined the moisture content in five samples. The average values thus obtained were considered the final results of moisture content determination.

The density of the obtained pellets was determined $24 \mathrm{~h}$ after process completion. It consisted of measuring the diameter and length of 15 randomly picked pellets (with an accuracy of $\pm 0.02 \mathrm{~mm}$ ) and then weighing these on a WPS 360 laboratory balance (with an accuracy of $\pm 0.001 \mathrm{~g}$ ). The density of pellets $\left(\rho_{g}\right)$ was calculated as the pellets mass to volume ratio.

This paper presents the results of tests of the influence of the moisture content of nettle waste $\left(w_{1}=15 \%, \mathrm{w}_{2}=18 \%\right.$, and $\left.\mathrm{w}_{3}=21 \%\right)$ and the process temperature $\left(\mathrm{t}_{1}=50^{\circ} \mathrm{C}, \mathrm{t}_{2}=70^{\circ} \mathrm{C}\right.$, $t_{3}=90^{\circ} \mathrm{C}$ ) on the values of densification work and the density of pellets produced in the pelleting processes of nettle waste and pre-densified mixtures of nettle waste and potato starch. In the course of the densification of pre-densified pellets from a mixture of nettle waste and potato starch, the impact of pellets particle size $\left(d_{f 1}=1 \mathrm{~mm}, d_{f 2}=2 \mathrm{~mm}\right.$, and $\left.d_{f 3}=3 \mathrm{~mm}\right)$ and process temperature $\left(t_{1}=50^{\circ} \mathrm{C}, t_{2}=70^{\circ} \mathrm{C}\right.$, 


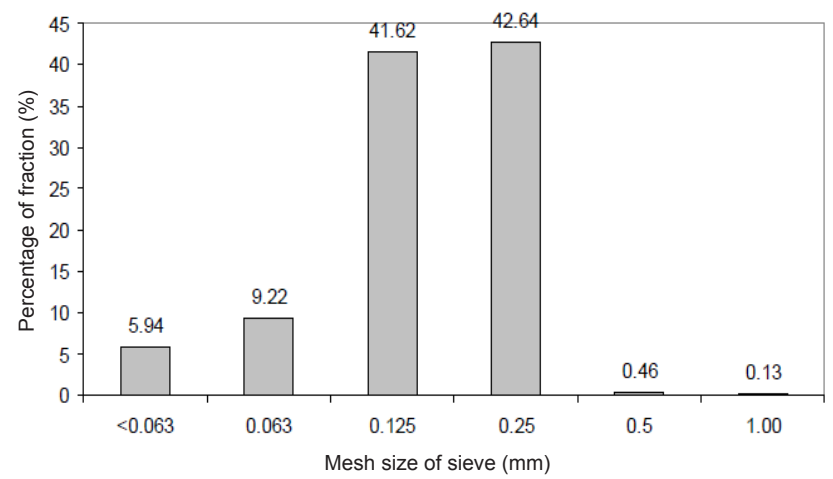

Fig. 1. Granulometric distribution of particles of shredded nettle waste subjected to a sieve analysis.

$t_{3}=90^{\circ} \mathrm{C}$ ) on the values of densification work and density of pellets were determined. The tests were performed at a matrix length of $l=47 \mathrm{~mm}$ and a mass of the densified mixture of $m_{p}=0.6 \mathrm{~g}$.

The sieve analysis of fine-grained nettle waste was performed on an LPz-2e Multiserw Morek laboratory vortex mixer (in line with PN-89/R-64798), using a set of 5 sieves: $1,0.5,0.25,0.125$, and $0.063 \mathrm{~mm} .100 \mathrm{~g}$ of the prepared material was weighed, poured onto the uppermost sieve and covered with a lid, and the vortex mixer was switched on for $5 \mathrm{~min}$. After this time, each fraction was weighed. The obtained results represented the proportional content of a given fraction.

The LPz-2e Multiserw Morek vortex mixer was also used to divide into fractions the pellets (of a mixture of nettle and binder material) which had been pre-densified in the process of coating. Sieves with openings of 1, 2, and $3 \mathrm{~mm}$ were used to this end.

\section{RESULTS AND DISCUSSION}

Figure 1 shows the granulometric distribution of particles of nettle waste subjected to sieve analysis on an LPZ-2e vortex mixer.

On the basis of the sieve analysis, we can conclude that the highest mass content was obtained for the fraction with a $0.25 \mathrm{~mm}$ opening size, comprising $42.64 \%$ of the total mass of the tested sample. A similar fraction mass was recorded on a sieve with a $0.125 \mathrm{~mm}$ opening size, comprising $41.62 \%$ of the total mass. The smallest amounts were observed for fractions on the sieves with opening sizes of 0.5 and $1 \mathrm{~mm}$. Both fractions combined amounted to less than $1 \%$.

The results of the effect of the moisture content in waste material and the process temperature on the densification work of nettle waste in an open chamber are presented on Fig. 2.

The tests showed that an increase in the temperature of the densification process from 50 to $90^{\circ} \mathrm{C}$ coincided with a reduction in densification work. For example, an increase in the process temperature from 50 to $90^{\circ} \mathrm{C}$, at a moisture content of $15 \%$, caused a significant reduction in densification work, from 18.53 to $1.91 \mathrm{~J}$ (i.e. by approximately $89 \%)$.

The test results allow the conclusion that densification work decreases as the moisture content in waste material increases from 15 to $21 \%$ (at each of the tested process temperatures). For example, an increase in moisture content from 15 to $21 \%$ (at a process temperature of $70^{\circ} \mathrm{C}$ ) causes a reduction in densification work from 28.09 to $23.37 \mathrm{~J}$ (by approximately 17\%).

The effect of moisture content in waste $\left(w_{o}\right)$ and the temperature of the densification process $\left(t_{p}\right)$ on the densification work $\left(L_{z}\right)$ of nettle waste in an open chamber is described by the following formula:

$$
L_{z}=-198.32+10.40 w_{o}+4.25 t_{p}-0.15 w_{o}^{2}-0.07 w_{o} t_{p}-0.03 t_{p}^{2} \text {. }
$$

The test results are confirmed by the results obtained by Laskowski and Skonecki (2001), who pelleted grains of four barley cultivars. They discovered that the values of densifying pressures and specific densification work decrease with increasing temperature.

According to Filbakk et al. (2011), an increase in the temperature of the material improves its flexibility and makes densification easier, particularly when combined with an increase in moisture content. Moreover, higher matrix temperatures are mainly caused by friction during the pelleting process.

Figure 3 presents the results of the tests of the effect of material and process factors (process temperature and the moisture content in pellets) on the density of pellets obtained from nettle waste in the process of open-chambered pressure agglomeration.

An analysis of test results shows that as the process temperature increases from 50 to $90^{\circ} \mathrm{C}$, pellet density decreases (at each of the tested moisture content values). For example, an increase in the process temperature from 50 to $90^{\circ} \mathrm{C}$, at a moisture content of $15 \%$, brings about a significant reduction in pellet density, from 1123.97 to $698.28 \mathrm{~kg} \mathrm{~m}^{-3}$ (i.e. by approximately $38 \%$ ).

The tests demonstrated that pellet density increased as the moisture content in pellets increased from 15 to $21 \%$ (at each of the tested process temperatures). For example, an increase in the moisture content from 15 to $21 \%$ (at a temperature of $90^{\circ} \mathrm{C}$ ) induces an increase in pellet density from 698.28 to $1183.23 \mathrm{~kg} \mathrm{~m}^{-3}$ (i.e. by approximately $41 \%$ ).

Larsson and Rudolfsson (2012) claim that controlling matrix temperature is an efficient method of obtaining high bulk density and high pellet durability. This is corroborated by Nielsen et al. (2009), who claim that during the pelleting process, process temperature and moisture content were the key parameters determining the pelletisability of sawdust, and pellet hardness. Generally, increased temperature and moisture content reduced the densification work of the 


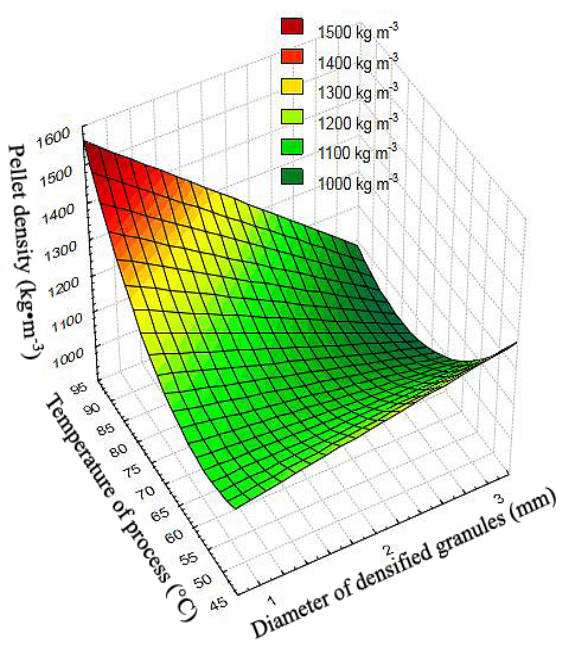

Fig. 2. Effect of material (the moisture content of pellets) and process (the temperature of the process) factors on the work of open-chambered nettle waste pressure densification.

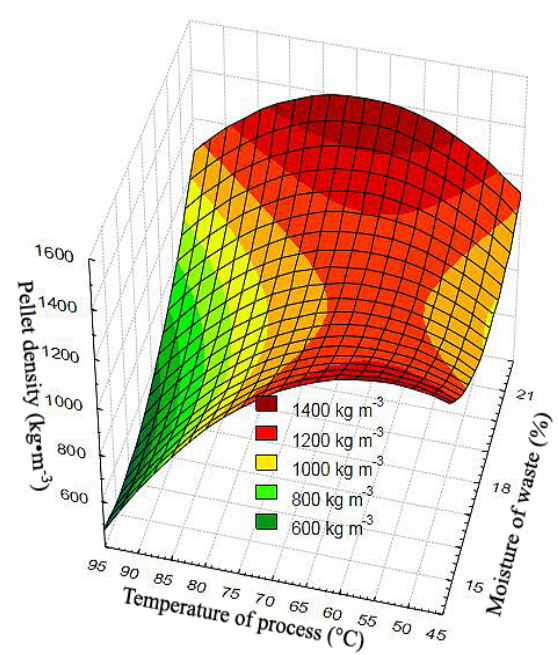

Fig. 3. Influence of material and process factors (the temperature of the process and the moisture content in pellets) on the density of pellets obtained in the process of open-chambered nettle waste pressure densification.

process. A higher temperature produced stronger pellets, while an increased moisture content may result in weaker pellets due to lowered wall friction.

According to Razuan et al. (2011), who investigated the physical properties of pellets made from palm kernel cake, the most favourable temperature for pellet production was $80-100^{\circ} \mathrm{C}$. These pellets had densities of $1184-1226 \mathrm{~kg} \mathrm{~m}^{-3}$ and tensile strengths of 930-1007 kPa. Carone et al. (2010) investigated the effect of key process parameters (pressure and temperature) and biomass characteristics (moisture content and particle size) on selected mechanical properties (density and durability) of pellets produced from olive tree pruning residues. They pelleted biomass with three different hammer mill screen sizes $(1,2$, and $4 \mathrm{~mm})$, at different moisture contents $(5,10,15$, and $20 \%$ w.b. $)$, process temperatures $\left(60,90,120\right.$, and $\left.150^{\circ} \mathrm{C}\right)$, and pressures $(71,106$, 141 , and $176 \mathrm{MPa}$ ) in a lab-scale pellet press. They discovered that temperature was the most important variable influencing the mechanical properties of pellets, followed by initial moisture content and raw material particle size. In particular, a high process temperature, a low moisture content, and a reduced particle size provided high quality pellets.

Li et al. (2015), who investigated energy input and physical properties of pellets made from sewage sludge and biomass, concluded that temperature and moisture content both had an impact, to various extents, on the properties of the discussed pellets, which were found to have been independent of pressure. For co-pelleting and an optimum pellet quality, they recommended a pressure of $55 \mathrm{MPa}$, a temperature of $90^{\circ} \mathrm{C}$, and a moisture content of $10-15 \%$ as the optimum parameters.

The effect of moisture content in pellets $\left(w_{o}\right)$ and process temperature $\left(t_{p}\right)$ on the density of pellets $\left(\rho_{g}\right)$ obtained during open-chambered nettle waste densification is described by the following formula:

$\rho_{g}=5511.41-587.38 w_{o}+26.67 t_{p}+13.34 w_{o}{ }^{2}+1.91 w_{o} t_{p}-0.49 t_{p}{ }^{2}$.

Tests of the pressure densification of nettle waste (moistened up to moisture contents of, respectively, 15, 18, and $21 \%$ ) in an open chamber (on an SS-3 stand) show that nettle waste is too fine-grained a material and thus not susceptible to densification. An agglomerate of a sufficient quality could not be obtained at any of the different values of moisture content and temperature. Indeed, at the highest temperature of $90^{\circ} \mathrm{C}$, the pellets crumbled immediately after leaving the matrix. For this reason, we decided to use binder material, in the form of a 5\% starch solution, in further tests, and to employ two-stage pelleting, i.e. pelleting which involves non-pressure agglomeration with the use of a flat-plate pellet mill in the first stage, followed by, i.e. pressure agglomeration, in the second stage.

Figure 4 shows the results of tests of the effect of material (fraction particle size) and process (process temperature) factors on the open-chambered densification work of pellets (as obtained in a non-pressure manner through coating) from a mixture of nettle waste and a $5 \%$ potato starch solution.

On the basis of the tests, we found that the densification work (at each of the tested fraction particle sizes) increased as the temperature of the densification process increased from 50 to $70^{\circ} \mathrm{C}$. For example, an increase in the densification temperature from 50 to $70^{\circ} \mathrm{C}$ at a fraction particle size of $1 \mathrm{~mm}$ brought about an increase in the densification work from 36.43 to $78.56 \mathrm{~J}$ (i.e. by approximately $54 \%$ ). A further increase in the process temperature from 70 to $90^{\circ} \mathrm{C}$ engendered a reduction in the densification work. For example, an increase in the process temperature from 70 to 
$90^{\circ} \mathrm{C}$ at a fraction particle size of $1 \mathrm{~mm}$ caused a reduction in the densification work from 68 to $25 \mathrm{~J}$ (i.e. by approximately $63 \%$ ).

Furthermore, increasing the particle size of densified pellets from 1 to $3 \mathrm{~mm}$ induced a reduction in the densification work at each of the tested process temperatures. The highest reduction in densification work, from 78.56 to $20.17 \mathrm{~J}$ (i.e. by approximately $74.32 \%$ ), was obtained when the pellet particle diameter increased from 1 to $3 \mathrm{~mm}$ (at a temperature of $70^{\circ} \mathrm{C}$ ).

The results of the tests concerning the effect of temperature and particle sizes of material on the process of the densification of nettle waste with potato starch content are comparable with the results obtained by other researchers.

Montero et al. (2014) who pelleted powder from cork industries, claimed that mixing different particle sizes was not an obstacle during the pelleting process, and no pretreatment (drying, sifting, etc.) was required in any of the cases, which in turn resulted in reduced processing costs. They claim that raw materials and different mixtures of cork can be pelleted regardless of the real demand for granulated cork (0.5-1, 1-2 mm, etc.).

Shaw et al. (2009) investigated the effect of a reduced particle size (an average of 0.3-0.6 $\mathrm{mm}$ after pelleting), two temperature values $\left(70-100^{\circ} \mathrm{C}\right)$, and two moisture content levels $(9-15 \%)$ on the density and mechanical resistance of pellets (produced in a laboratory press) from wheat straw and poplar wood. They discovered that under all these conditions, smaller particle sizes resulted in higher pellet densities and mechanical resistances. Gilbert et al. (2009) studied the effect of pressure and temperature on the density and mechanical resistance of pellets from wheat straw and grass. Their study showed that at temperatures between 75 and $100^{\circ} \mathrm{C}$, lignin melts act as a natural binder and a maximum resistance is obtained. However, above $100^{\circ} \mathrm{C}$, water evaporates and pellets become more brittle.

Nguyen et al. (2015) investigated the effect of process parameters and raw material characteristics on the physical and mechanical properties of wood pellets made from particles of sugar maple trees (of different vigour) in a single pellet mill, while controlling temperature $(75,100$, and $\left.125^{\circ} \mathrm{C}\right)$, moisture content $(8.1,11.2$, and $17.2 \%)$, densifying force $(1500,2000$, and $2500 \mathrm{~N})$, and particle size $(<0.25$, $0.25-0.5$, and $0.5-1.0 \mathrm{~mm}$ ). Particle size was the most important factor for the friction in the matrix, followed by moisture content, densifying force and temperature. They claim that in order to minimise friction, and, consequently, maximise the density and compressive strength of the produced pellets, the pelleting process should take place at a temperature of approximately $100^{\circ} \mathrm{C}$ and at a moisture content of approximately $11.2 \%$.
According to Kashaninejad et al. (2014), the total specific energy required for the densification and ejection of pellets (a matrix diameter of $6.35 \mathrm{~mm}$ ) made from wheat straw grinds, varied from 4.35 to $33.64 \mathrm{MJ} \mathrm{t}^{-1}$ and increased with compressive load and particle size (less than $1 \mathrm{~mm}$ ).

The effect of fraction particle diameter $\left(d_{f}\right)$ and densification process temperature $\left(t_{p}\right)$ on the densification work temperature $\left(L_{z}\right)$ of pellets (obtained in an open-chambered non-pressure manner from nettle waste with a starch solution) is described by the following formula:

$$
L_{z}=-170.66-8.01 d_{f}+7.08 t_{p}-5.02 d_{f}{ }^{2}+0.21 d_{f} t_{p}-0.06 t_{p}{ }^{2},
$$

$d_{f}$ - fraction particle diameter $(\mathrm{mm})$.

Figure 5 illustrates the results of tests of the effect of material and process factors (process temperature and densified fraction particle diameter) on the density of pellets obtained in the process of open-chambered pressure agglomeration, from a raw material in the form of nettle waste pellets produced in a non-pressure manner through coating with a $5 \%$ potato starch solution.

An analysis of Fig. 5 leads one to the conclusion that the density of pellets increased (at each of the tested fraction particle sizes) as the densification process temperature increased from 50 to $90^{\circ} \mathrm{C}$. For example, an increase in the temperature of the densification process from 50 to $90^{\circ} \mathrm{C}$, at a fraction particle size of $1 \mathrm{~mm}$, caused an increase in pellet density from 1110.44 to $1364.46 \mathrm{~kg} \mathrm{~m}^{-3}$ (i.e. by approximately $19 \%$ ). Only at a particle size of $3 \mathrm{~mm}$ did an increase in temperature (from 50 to $70^{\circ} \mathrm{C}$ ) result in a reduced pellet density. The obtained reduction was attributable to the increased moisture content in pellets (obtained in a non-pressure manner) (Fig. 6).

The excessive moisture content (approximately 23\%) of the densified $3 \mathrm{~mm}$ fraction caused depressurisation - as a result of the high pressures and high temperatures in the chamber - of the pellets which had left the densification chamber.

Excessive moisture content (approximately 23\%) of the densified $3 \mathrm{~mm}$ fraction caused depressurisation of the pellets that left the densification chamber, due to the high pressures and high temperatures in the chamber.

The tests (Fig. 5) showed that as the particle size of densified pellets increased from 1 to $3 \mathrm{~mm}$, a reduction in pellet density (at process temperatures of 70 and $90^{\circ} \mathrm{C}$ ) occurred. The obtained reduction was also attributable to the excessive moisture content in pellets obtained in a non-pressure manner (Fig. 6), with moisture levels being approximately: 23 and $21 \%$ for the 3 and $2 \mathrm{~mm}$ fraction, respectively. Such high moisture levels brought about the depressurisation of the pellets which had left the densification chamber, thus reducing their density. Only at a process temperature of $50^{\circ} \mathrm{C}$ does an increase in the particle size of pellets from 1 to $3 \mathrm{~mm}$ create an increase in pellet density, from 1110.44 to $1184.16 \mathrm{~kg} \mathrm{~m}^{-3}$ (i.e. by approximately $6 \%$ ). The highest pellet density $\left(1364.46 \mathrm{~kg} \mathrm{~m}^{-3}\right)$ was obtained 


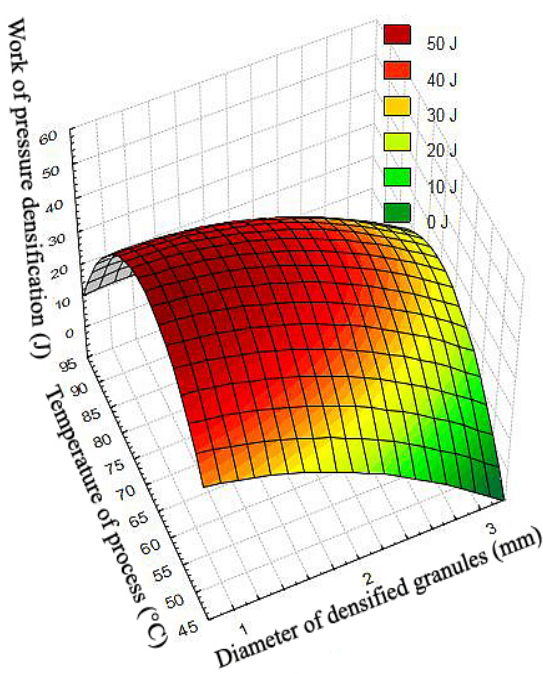

Fig. 4. Effect of material (the size of fraction particles) and process (the temperature of the process) factors on the work of open-chambered pressure densification of pellets (obtained in a non-pressure manner through enveloping) from a mixture of nettle waste and a $5 \%$ potato starch solution.

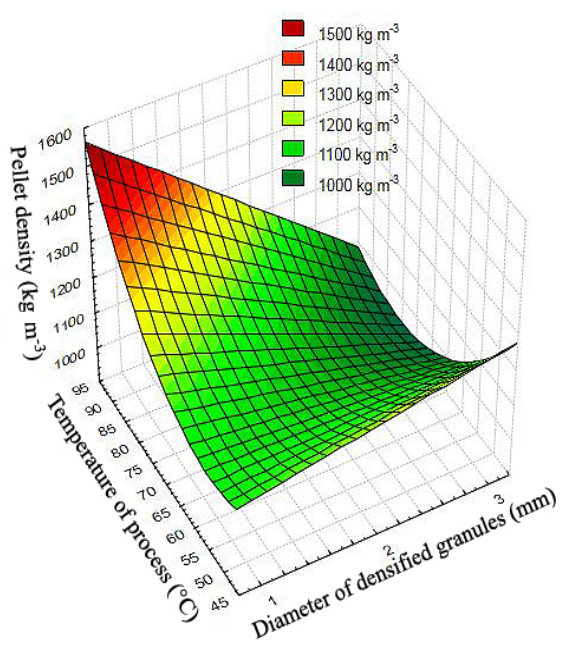

Fig. 5. Effect of material and process factors (the diameter of particles of the densified fraction and process temperature) on the density of pellets obtained in the process of open-chambered pressure agglomeration, of pellets (obtained in a non-pressure way) from nettle waste and a 5\% potato starch solution.

at a temperature of $90^{\circ} \mathrm{C}$ and a fraction diameter size of $1 \mathrm{~mm}$. The tests showed that increased pellet density was strongly correlated with a reduction in the moisture content in the densified pellets (as obtained in a non-pressure manner from a mixture of nettle waste and a starch solution).

The effect of fraction particle diameter $\left(d_{f}\right)$ and process temperature $\left(t_{p}\right)$ on the density of pellets $\left(\rho_{g}\right)$ obtained through densification in an open chamber (produced in a non-pressure manner from a mixture of nettle waste and a starch solution) is described by the following formula:

$\rho_{g}=1683.69+314.17 d_{f}-25.03 t_{p}+0.73 d_{f}{ }^{2}-5.87 d_{f} t_{p}+0.27 t_{p}^{2}$

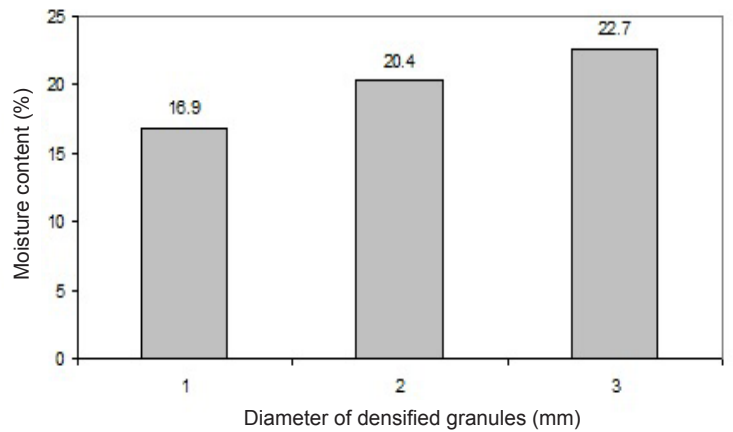

Fig. 6. Correlation between moisture content and the size of particles of pellets from a mixture of nettle waste and a $5 \%$ potato starch solution obtained in a non-pressure way.

The tests showed that at a temperature of $70^{\circ} \mathrm{C}$, across the range of fraction particle diameters, pellets of a sufficient density failed to be produced. They crumbled at a slight press of the hand. Conversely, at a temperature of $90^{\circ} \mathrm{C}$, across the range of pellet sizes, pellets of a sufficient density (from 968.78 to $1364.46 \mathrm{~kg} \mathrm{~m}^{-3}$ ) were successfully produced.

The tests allowed us to conclude that the two-stage pelleting of fine-grained nettle waste, in which the waste was pre-densified in the process of coating with a binder addition and then subjected to pressure agglomeration, resulted in increased work required for waste densification, from 0.87-34.28 J (in the case of pressure densification of nettle waste alone) to $6.58-78.56 \mathrm{~J}$ (in the case of the pressure densification of pellets obtained in a non-pressure manner from nettle waste and a 5\% potato starch solution). Adding a binder material (in the form of starch) to nettle waste in the process of non-pressure agglomeration prior to pressure pelleting resulted in increased densifying pressures and, in consequence, increased densification work (compared to the densification of nettle waste alone). In their studies, Stasiak et al. (2013) corroborated the very good properties of starch as a natural binder.

The obtained results of tests of the pressure densification of nettle waste with potato starch content are comparable with the results obtained by other studies dealing with biomass densification with binder materials. According to Kaliyan and Morey (2010), natural binders in biomass can be expressed or activated (softened) under high pressures in the presence of moisture (e.g. water soluble carbohydrates) or, in some cases, an increased temperature. Pre-densified nettle waste, in the course of pressure densification, on contact with surfaces of matrix openings, resulted in increased resistance to forcing (the mixture no longer slid on opening surfaces, as was the case when nettle waste was densified alone), yielding high-density pellets.

The use of the two-stage pelleting of fine-grained nettle waste, in which the waste is pre-densified in the process of coating with a binder addition and then subjected to pressure agglomeration, substantially increases the density of pellets. During the pressure densification of nettle waste 
alone, densities ranging from 491.77 to $1212.61 \mathrm{~kg} \mathrm{~m}^{-3}$ were obtained, while in the course of the pressure densification of pellets (obtained in a non-pressure manner) from nettle waste and a $5 \%$ potato starch solution, densities ranged from 968.78 to $1364.46 \mathrm{~kg} \mathrm{~m}^{-3}$.

The positive effect of binder addition to biomass on the quality of pellets in the pelleting process has been corroborated by many studies. Finney et al. (2009) concluded that the kinetic durability of pellets increased considerably when small amounts (over 1\%) of binder (sodium hydroxide and maize starch) were added during biomass pelleting. Razuan et al. (2011) discovered that adding small amounts of caustic soda (1.5-2.0 wt.\%) to palm kernel cake increased the tensile strength of the obtained pellets. Gilbert et al. (2009), who produced pellets from a mixture of switchgrass and heavy oil, concluded that heavy pyrolysis oil is of potential use as a binder material that can substantially increase pellet strength and durability. Ohman et al. (2006) observed that it was possible to improve the quality of pellets produced from biomass by adding hydrolytic post-production waste obtained during the production of ethanol from lignocellulosic materials. Sotannde et al. (2010) concluded that using binding materials (gum arabic and Cassava starch) in the process of the densification (briquetting) of carbonised (torrefied) forest wood waste allows the production of briquettes of a high kinetic durability. According to Filbakk et al. (2011), higher contents of lignin and extractives have a positive effect on binding mechanisms during the production of pellets from pinewood containing $0,5,10,30$, and $100 \%$ of bark.

\section{CONCLUSIONS}

The tests involving the non-pressure and pressure pelleting of a mixture of nettle waste and a binder in the form of a starch solution led to the following conclusions:

1. The addition of a binder to nettle waste yielded high density pellets, pressure-produced from pellets obtained earlier in a non-pressure manner. The densities of nettle waste with a starch solution pellets ranged from 972.15 to $1364.46 \mathrm{~kg} \mathrm{~m}^{-3}$.

2. An increase in the fraction particle diameter of pellets obtained through non-pressure densification from nettle waste with a starch solution from 1 to $3 \mathrm{~mm}$ resulted in a reduced densification work and an increased density of pellets obtained in the process of pressure agglomeration.

3. An increase in the temperature of the densification process of nettle waste and starch solution pellets obtained in a non-pressure manner, from 50 to $90^{\circ} \mathrm{C}$, brought about an increase in densification work and pellet density.

4. The most beneficial value of pellet density (1364.46 $\mathrm{kg} \mathrm{m}^{-3}$ ) obtained in the process of pressure densification (in a non-pressure manner) from a mixture of nettle waste and a starch solution was achieved at a process temperature of $90^{\circ} \mathrm{C}$ and a fraction particle diameter of $1 \mathrm{~mm}$.
5. The introduction of a binder material and two-stage agglomeration to the process of nettle waste densification resulted in an increased pellet density and increased densification work, when compared to the densification of nettle waste alone (at the same time, the greatest amount of energy was used for waste densification).

Conflict of interest: The Authors do not declare conflict of interest.

\section{REFERENCES}

Carone M.T., Pantaleo A., and Pellerano A., 2010. Influence of process parameters and biomass characteristics on the durability of pellets from the pruning residues of Olea europaea L. Biomass and Bioenergy, 30, 1-9.

Chou C.S., Lin S.H., and Lu W.C., 2009. Preparation and characterization of solid biomass fuel made from rice straw and rice bran. Fuel Processing Technol., 90, 980-987.

Filbakk T., Jirjis R., Nurmi J., and Høibø O., 2011. The effect of bark content on quality parameters of Scots pine (Pinus sylvestris L.) pellets. Biomass Bioenergy, 35, 3342-3349.

Finney K.N., Sharifi V.N., and Swithenbank J., 2009. Fuel pelletisation with a binder: Part I - Identification of a suitable binder for spent mushroom compost - coal tailing pellets. Energy Fuels, 23, 3195-3202.

Flore K., Schoenherr M., and Feise H., 2009. Aspects of granulation in the chemical industry. Powder Technol., 189, 327-331.

Gilbert P., Ryu C., Sharifi V., and Swithenbank J., 2009. Effect of process parameters on pelletisation of herbaceous crops. Fuel, 88, 1491-1497.

Hanczakowska E., 2007. Herbs and herb preparations in pig feeding (in Polish). Zootechnical Messages, 45(3), 19-23.

Herting M.G. and Kleinebudde P., 2007. Roll compaction/dry granulation: Effect of raw material particle size on granule and tablet properties. Int. J. Pharmaceutics, 7, 338, 110-118.

Hryniewicz M., Bembenek M., and Gara P., 2008. Problem of roll press compacting unit selection to consolidate material in two-stage granulation process. Chemik, 61, 9, 425-428.

Gluba T., 2003. The effect of wetting liquid droplet size on the growth of agglomerates during wet drum granulation. Powder Technology, 130, 219-224.

Gluba T. and Obraniak A., 2009. The kinetics of agglomeration of particulate material in the disc granulator (in Polish). Inżynieria i Aparatura Chemiczna, 48, 4, 46-47.

Hejft R. and Leszczuk T., 2011. Selection of process parameters for no-pressure agglomeration (encapsulation of seeds). Part I: Experimental stand (In Polish). Inżynieria i Aparatura Chemiczna, Nr 1/2011, 15-16.

Kaliyan N. and Morey RV., 2010. Natural binders and solid bridge type binding mechanisms in briquettes and pellets made from corn stover and switchgrass. Bioresource Technol., 101, 1082-1090.

Kashaninejad M., Tabil L.G., and Knox R., 2014. Effect of compressive load and particle size on compression characteristics of selected varieties of wheat straw grinds. Biomass Bioenergy, 60, 1-7. 
Larsson S.H. and Rudolfsson M., 2012. Temperature control in energy grass pellet production: Effects on process stability and pellet quality. Applied Energy, 97, 24-29.

Laskowski J. and Skonecki S., 2001. Influence of material's temperature on compression parameters of ground barley grains. International Agrophysics, 15, 173-179.

Li H., Jiang L.B., Li C.Z., Liang J., Yuan X.Z., Xiao Z.H., Xiao Z.H., and Wang H., 2015. Co-pelletization of sewage sludge and biomass: The energy input and properties of pellets. Fuel Processing Technol., 132, 55-61.

Mani S., Lope G., Tabil L.G., and Sokhansanj S., 2006a. Effects of compressive force, particle size and moisture content on mechanical properties of biomass pellets from grasses. Biomass Bioenergy, 30, 648-654.

Mani S., Tabil L.G., and Sokhansanj S., 2006b. Specific energy requirement for compacting corn stover, Bioresource Technol., 97, 1420-1426.

Mediavilla I., Fernández M.J., and Esteban L.S., 2009. Optimization of pelletisation and combustion in a boiler of $17.5 \mathrm{kWth}$ for vine shoots and industrial cork residue, Fuel Processing Technol., 90, 621-628.

Monedero E., Portero H., and Lapuerta M., 2015. Pellet blends of poplar and pine sawdust: Effects of material composition, additive, moisture content and compression die on pellet quality. Fuel Processing Technol., 132, 15-23.

Montero I., Miranda T., Sepúlveda F.J., Arranz J.I., and Nogales S., 2014. Analysis of pelletizing of granulometric separation powder from cork industries. Materials, 7, 6686-6700.

Nguyen Q.N., Cloutier A., Achim A., and Stevanovic T., 2015. Effect of process parameters and raw material characteristics on physical and mechanical properties of wood pellets made from sugar maple particles. Biomass Bioenergy, 80, 338-349.

Niedziółka I., Szymanek M., Zuchniarz A., and Zawiślak K., 2008. Characteristics of pellets produced from selected plants mixes. TEKA Komisji Motoryzacji i Energetyki Rolnictwa. OL PAN, 8, 157-162.

Nielsen N.P.K., Holm J.K., and Felby C., 2009. Effect of fiber orientation on compression and frictional properties of sawdust particles in fuel pellet production. Energy Fuel, 23, 3211-3216.

Obidziński S., 2012a. Pelletization process of postproduction plant waste. Int. Agrophys., 26, 279-284.

Obidziński S., 2012b. Analysis of usability of potato pulp as solid fuel. Fuel Processing Technology. Fuel Processing Technol., 94, 67-74.

Obidzinski S., 2014a. Pelletisation of biomass waste with potato pulp content. Int. Agrophys., 28, 85-91.

Obidziński S., 2014b. Utilization of post-production waste of potato pulp and buckwheat hulls in the form of pellets. Polish J. Environ. Stud., 23, 1391-1395.
Obidziński S., Piekut J., and Dec D., 2016. The influence of pulp content on the properties of pellets from buckwheat hulls. Renewable Energy, 87, 289-297.

Obraniak A. and Gluba T., 2011. A model of granule porosity changes during drum granulation, Physicochemical Problems Mineral Proc., 46, 219-228.

Ohman M., Boman C., Hedman H., and Eklund R., 2006. Residential combustion performance of pelletized hydrolysis residue from lignocellulosic ethanol production. Energy Fuels, 20, 298-304.

Paschma J., 2004. Effect of using herbs in diets of periparturient sows on the course of parturition and reproductive performance. Annals Animal Sci., Suppl. 1, 293-295.

Payne J., Rattink W., Smith T., and Winowiski T., 2001. Pelleting Handbook. A Guide for production staff in the compound feed industry. Borregaard Lignotech.

PN-89/R-64798. Feeds. Determination of disintegration (in Polish).

PN-EN 14774-1: 2010. Solid biofuels. - Determination of moisture content. Drier method. Part 1: Total moisture - Reference method.

Razuan R., Finney K.N., Chen Q., Sharifi V.N., and Swithenbank J., 2011. Pelletised fuel production from palm kernel cake, Fuel Processing Technol., 92, 609-615.

Robohm K.F. and Apelt J., 1989. Verhoging van de flexibiliteit door gebruik van het perssysteem met voorverdichting. De Molenaar, 92, 615-625.

Ryu C., Finney K., Sharifi V.N., and Swithenbank J., 2008. Pelletised fuel production from coal tailings and spent mushroom compost - Part I: Identification of pelletisation parameters, Fuel Processing Technol., 89, 269-275.

Shaw M.D., Karunakaran C., and Tabil L.G., 2009. Physicochemical characteristics of densified untreated and steam exploded poplar wood and wheat straw grinds. Biosystems Eng., 103, 198-207.

Shipe K.J., Evans A.M., Wamsley K.G.A., and Moritz J.S., 2012. Pelleting does not decrease lysine digestibility. Poultry Science, 91 (Suppl. 1, Abstr. 132).

Sobczak P., 2004. Agglomeration of selected food powder materials (in Polish). Ph.D. Thesis, Agricultural University of Lublin, Poland.

Sotannde O.A., Oluyege A.O., and Abah G.B., 2010. Physical and combustion properties of charcoal briquettes from neem wood residues. Int. Agrophys., 24, 189-194.

Stasiak M., Molenda M., Opaliński I., and Błaszczak W., 2013. Mechanical properties of native maize, wheat, and potato starches. Czech J. Food Sci., 31(4), 347-354.

Wildeboer W.J., Litster J.D., and Cameron I.T., 2005. Modelling nucleation in wet granulation. Chemical Eng. Sci., 60, 3751-3761. 